\title{
ТЕРРИТОРИАЛЬНАЯ ДИФФЕРЕНЦИАЦИЯ УРОВНЯ ЗАБОЛЕВАЕМОСТИ НАСЕЛЕНИЯ КАМЧАТСКОГО КРАЯ (СРАВНИТЕЛЬНЫЙ АСПЕКТ)
}

\author{
Погорелов А.P. \\ Дальневосточный федеральный университет, Владивосток \\ Тихоокеанский институт географии ДВО РАН, Владивосток \\ pogorelov_ar@mail.ru
}

Аннотащия. Актуальность изучения пространственных аспектов заболеваемости обусловлена прежде всего современной общественной значимостью охраны здоровья населения. Цель представленного исследования заключалась в территориально-дифференцированной сравнительной оценке общей заболеваемости населения Камчатского края в разрезе административных районов. Для сравнительной оценки уровня заболеваемости населения в административных районах Камчатского края выбраны два однолетних временных периода (2011 и 2018 гг.) и произведен расчет сумм установленных значений по 17 основным классам болезней МКБ-10. В дальнейшем произведено итоговое ранжирование исследуемых административно-территориальных единиц Камчатского края. Все районы распределены на пять групп по уровню общей заболеваемости населения (очень низкий, низкий, средний, высокий, очень высокий). В 2011 г. в группу очень высокого уровня общей заболеваемости вошли 4 района, высокого уровня -4 , среднего уровня -1 , низкого уровня -1 и очень низкого уровня - 3. В 2018 г. в группу очень высокого уровня общей заболеваемости вошли 4 района, высокого уровня -2 , среднего уровня -1 , низкого уровня -3 , очень низкого - 3. Выявлено, что устойчивую позитивную позицию в 2011 и 2018 гг. сохраняет г. Вилючинск, который отличается очень низким уровнем заболеваемости. Олюторский и Тигильский районы устойчиво сохраняют негативную позицию в 2011 и 2018 гг. в группе районов с очень высоким уровнем общей заболеваемости населения. Вместе с тем обнаружено, что в Камчатском крае в 2011 и 2018 гг. сохраняется напряженность по заболеваемости населения болезнями органов дыхания, пищеварения, травмами и отравлениями, по которым в последнем исследуемом году в 9 районах наблюдалась заболеваемость выше среднего по региону. Наименее напряженная ситуация отмечена для класса врожденных аномалий и новообразований, по которым в 2011 и 2018 гг. соответственно наблюдалась заболеваемость населения выше среднего по региону.

Ключевые слова: заболеваемость, территориальная дифференциация, здоровье населения, сравнительный анализ, Камчатский край. 


\title{
TERRITORIAL DIFFERENTIATION \\ OF POPULATION DISEASE RATE IN THE KAMCHATKA REGION (COMPARATIVE ASPECT)
}

\author{
Pogorelov A.R. \\ Far Eastern Federal University, Vladivostok \\ Pacific Geographical Institute of the FEB RAS, Vladivostok
}

Annotation. The topicality of the study of spatial aspects of the population disease rate is determined by social and economic importance of public health protecting. The purpose of this study lies in territorial assessment of the population disease rate of the Kamchatka Region by administrative districts. A comparative territorial assessment was carried out for two years (2011 and 2018). Values were established for the main classes of diseases for all administrative districts of the Kamchatka Region. The final rating is compiled for the studied administrative-territorial units of the Kamchatka Region. This rating included five territorial groups on disease incidence rate (very high, high, medium, low, very low). In 2011, all the districts were distributed in the following order: very high -4 , high -4 , medium -1 , low -1 , very low -3 . In 2018, all the districts were distributed in the following order: very high -4 , high -2 , medium -1 , low -3 , very low -3 . A stable positive position is typical for one district (Vilyuchinsk). A stable negative position is typical for two districts of Koryakia (Olyutorsky, Tigilsky). We also found a negative regional situation in the population disease rate by three disease classes in 2011 and 2018 (diseases of the respiratory system; diseases of the digestive system; injury, poisoning and certain other consequences of external causes). Two disease classes (neoplasms; congenital malformations, deformations and chromosomal abnormalities) are characterized by the lowest prevalence in districts of the Kamchatka Region.

Key words: health, morbidity, disease rate, territorial differentiation, comparative geographical aspect, Kamchatka, Russia.

В последних исследованиях национального уровня [2-3] установлено, что Камчатский край среди других регионов России отличается очень низким уровнем общественного здоровья населения. Вместе с тем, каждый российский регион, включая территорию Камчатского края, имеет внутренние региональные различия в состоянии здоровья населения и его отдельных показателей. Заболеваемость населения является важнейшим показателем, который позволяет охарактеризовать и оценить состояние общественного здоровья, а также медико-демографические особенности исследуемой территории. Актуальность изучения территориальных особенностей в уровне заболеваемости населения Камчатского края определена необходимостью улучшения существующих мер охраны здоровья местного населения и повышения его качества жизни. 
Цель настоящей работы заключалась в территориально-дифференцированной оценке заболеваемости населения Камчатского края в разрезе административных районов. В основу оценки положены официальные медико-статистические данные Камчатского краевого медицинского информационно-аналитического центра [4-7]. Заболеваемость населения измерялась в \%о, т.е. в количестве всех зарегистрированных случаев заболеваний на 1000 человек населения.

В 2011-2018 гг. общая заболеваемость всего населения Камчатского края увеличилась на $2 \%$. Среднее значение за этот временной период составило 1585,5 \%о. Наибольший показатель текущей заболеваемости отмечается в Олюторском районе $(2648,0 \%$ ), наименьший показатель - в Вилючинске (1139,8 \%). В остальных районах Камчатского края общая заболеваемость колеблется от 1226,8 \%о (Соболевский район) до 2547,1 \% (Тигильский район). В региональной структуре общей заболеваемости населения преобладают болезни органов дыхания $(24,1 \%)$, системы кровообращения $(13,4 \%)$, костно-мышечной $(7,9 \%)$ и мочеполовой $(7,6 \%)$ систем.

Настоящая оценка заболеваемости населения Камчатского края построена на методике, освещенной в работе Т.В. Ватлиной [1], суть которой заключается в пространственно-временном анализе дифференциации заболеваемости населения за некоторый временной период. В нашем случае отдельно взяты два года (2011 и 2018 гг.), для которых определены средние арифметические по комплексу основных классов болезней по МКБ-10 (17 классов). Далее выделены две группы районов Камчатского края для каждого основного класса болезней с заболеваемостью ниже среднего показателя по региону (отсутствие признака - 0) и выше среднего по региону (наличие признака - 1). В дальнейшем для каждого района были просуммированы установленные значения по основным классам болезней, на основе чего проведено ранжирование исследуемых административно-территориальных единиц Камчатского края.

Полученные данные занесены в таблицы (табл. 1 и 2), в которых обозначены основные классы болезней: 1 - инфекционные заболевания; 2 - новообразования; 3 - болезни крови; 4 - эндокринные заболевания; 5 - психические расстройства; 6 - болезни системы кровообращения; 7 - болезни органов дыхания; 8 - болезни органов пищеварения; 9 - болезни нервной системы; 10 - болезни глаза; 11 болезни уха; 12 - болезни кожи; 13 - болезни костно-мышечной си- 
Общая заболеваемость всего населения Камчатского края (2011 г.)

\begin{tabular}{|c|c|c|c|c|c|c|c|c|c|c|c|c|c|c|c|c|c|c|c|}
\hline- & & \multicolumn{17}{|c|}{$\begin{array}{c}\text { Общая заболеваемость по основным классам } \\
\text { болезней }\end{array}$} & - \\
\hline- & - & 1 & 2 & 3 & 4 & 5 & 6 & 7 & 8 & 9 & 10 & 11 & 12 & 13 & 14 & 15 & 16 & 17 & $\sum$ \\
\hline \multirow{13}{*}{ 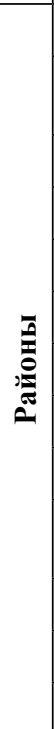 } & B & 0 & 0 & 0 & 0 & 0 & 0 & 0 & 0 & 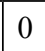 & 0 & . & م & 0 & 0 & 0 & 0 & 1 & 1 \\
\hline & $\begin{array}{l}\text { Усть- } \\
\text { Большерецкий } \\
\end{array}$ & 0 & 0 & 0 & 0 & 0 & 0 & 0 & 0 & 0 & 0 & 0 & 0 & 1 & 1 & 1 & 0 & 0 & 3 \\
\hline & Усть-Камчатски & . & 0 & 1 & 1 & U & 0 & 0 & 0 & 0 & 0 & 0 & 0 & & 1 & 0 & 0 & 0 & 3 \\
\hline & Елизовский & 0 & 0 & 0 & 1 & 0 & 0 & 1 & 1 & 1 & 0 & 0 & 0 & 0 & 0 & 0 & 0 & 0 & 4 \\
\hline & Алеутский & 0 & 0 & 1 & 1 & 1 & 0 & 1 & 1 & 0 & 0 & 0 & 0 & 0 & 0 & 1 & 1 & 0 & 7 \\
\hline & Быст & & 0 & 1 & 0 & 1 & 0 & 1 & 1 & 1 & 1 & 0 & 0 & & 0 & 1 & 0 & 1 & 9 \\
\hline & Мильковский & & 0 & 1 & 1 & 0 & 1 & 1 & 0 & 0 & 1 & 1 & 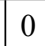 & 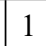 & 1 & 1 & 0 & 0 & 9 \\
\hline & Соболевский & 0 & 1 & 1 & 0 & 0 & 1 & 0 & 1 & 1 & 0 & 0 & 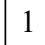 & 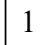 & 1 & 1 & 0 & 0 & 9 \\
\hline & Kap & & 1 & 1 & 1 & 1 & 0 & 1 & 1 & 0 & 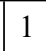 & 1 & 0 & 0 & 0 & 0 & 1 & 0 & 10 \\
\hline & $\begin{array}{l}\text { Петропавловс } \\
\text { Камчатский } \\
\end{array}$ & I & 1 & 0 & 0 & 1 & 1 & 0 & 0 & 0 & 1 & 1 & 1 & 1 & 1 & 1 & 1 & 1 & 12 \\
\hline & Олюторский & 1 & U & 1 & 0 & 1 & 0 & 1 & 1 & 1 & 1 & 1 & 1 & 0 & 1 & 1 & 0 & 1 & 12 \\
\hline & Тигильский & 1 & 1 & 1 & 1 & 1 & 1 & 1 & 1 & 0 & 1 & 1 & 0 & 0 & 1 & 1 & 0 & 0 & 12 \\
\hline & Пенжинский & 0 & 0 & 1 & 1 & 1 & 1 & 1 & 1 & 1 & 0 & 1 & 1 & 1 & 1 & 1 & 0 & 1 & 13 \\
\hline
\end{tabular}

стемы; 14 - болезни мочеполовой системы; 15 - травмы и отравления; 16 - врожденные аномалии; 17 - осложнения беременности и родов.

В результате расчетов все административные районы Камчатского края распределены на пять групп по уровню общей заболеваемости населения: 1) очень низкий; 2) низкий; 3) средний; 4) высокий; 5) очень высокий (рис. 1).

В 2011 г. очень высокий уровень заболеваемости отмечен в Пенжинском, Тигильском, Олюторском районах и г. Петропавловске-Камчатском, высокий уровень наблюдался в Карагинском, Быстринском, Соболевском и Мильковском районах, средний уровень в Алеутском районе, низкий уровень в Елизовском районе и очень низкий уровень в г. Вилючинске, Усть-Камчатском и Усть-Большерецком районах. В 2018 г. (в сравнении с 2011 г.) на основании принятой методики территориальная дифференциация уровня заболеваемости населения Камчатского края претерпела некоторые изменения. Очень высокий уровень общей заболеваемости зафиксирован в Олюторском, Ти- 
Та блица 2

Общая заболеваемость всего населения Камчатского края (2018 г.)

\begin{tabular}{|c|c|c|c|c|c|c|c|c|c|c|c|c|c|c|c|c|c|c|c|}
\hline - & & \multicolumn{17}{|c|}{$\begin{array}{c}\text { Общая заболеваемость по основным классам } \\
\text { болезней }\end{array}$} & \\
\hline- & - & 1 & 2 & 3 & 4 & 5 & 6 & 7 & 8 & 9 & 10 & 11 & 12 & 13 & 14 & 15 & 16 & 17 & $\sum$ \\
\hline \multirow{13}{*}{ ה } & Іино & 0 & 0 & 0 & 0 & & 0 & 1 & 0 & 0 & 0 & 1 & 0 & 0 & 0 & 0 & 0 & 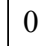 & 3 \\
\hline & Соболевск & 0 & 1 & 0 & 0 & 0 & 0 & 0 & 0 & 0 & 0 & 0 & 1 & 0 & 0 & 1 & 1 & ) & 4 \\
\hline & $\begin{array}{l}\text { Усть- } \\
\text { Большере }\end{array}$ & 0 & 0 & 0 & 0 & 0 & 0 & 0 & 1 & 0 & 1 & 0 & 0 & 0 & 0 & 1 & 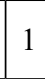 & 0 & 4 \\
\hline & Мильковский & 0 & 0 & 0 & 0 & & 1 & 1 & 0 & 0 & 0 & 0 & 1 & 1 & 1 & 0 & 0 & 0 & 5 \\
\hline & Усть-Камчат & 0 & 0 & 0 & 1 & 0 & 0 & 1 & 1 & 0 & 1 & 0 & 0 & 1 & 0 & 0 & 0 & 0 & 5 \\
\hline & Елизовский & 0 & 0 & 0 & 1 & 1 & 0 & 0 & 1 & 1 & 0 & 0 & 0 & 0 & 0 & 1 & 0 & 1 & 6 \\
\hline & Пенжинский & 1 & 0 & 1 & 0 & & 1 & 1 & 1 & 0 & 0 & 1 & 0 & 0 & 0 & 1 & 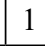 & 0 & 9 \\
\hline & $\begin{array}{l}\text { Петропавловск- } \\
\text { Камчатский }\end{array}$ & 1 & 1 & 1 & 0 & 0 & 1 & 0 & 0 & 0 & 1 & 1 & 1 & 1 & 1 & 0 & 1 & 1 & 11 \\
\hline & Быстринский & 0 & 0 & 0 & 1 & 1 & 1 & 1 & 1 & 1 & 1 & 1 & 0 & 1 & 0 & 1 & 0 & 1 & 11 \\
\hline & ский & 1 & 1 & 1 & 1 & 1 & 1 & 1 & 1 & 1 & 0 & 0 & 0 & 1 & 0 & 1 & 1 & 0 & 12 \\
\hline & Карагинский & 0 & 0 & 1 & 1 & 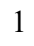 & 1 & 1 & 1 & 1 & 1 & 1 & 1 & 0 & 0 & 1 & 1 & 1 & |J \\
\hline & Тигильский & 1 & 0 & 1 & 1 & 1 & 1 & 1 & 1 & 1 & 1 & 1 & 1 & 0 & 1 & 1 & 0 & 0 & 13 \\
\hline & Олюторский & 1 & 0 & 1 & 1 & 1 & 1 & 1 & 1 & 1 & 1 & 1 & 1 & 1 & 1 & 1 & 0 & 0 & 1 \\
\hline
\end{tabular}

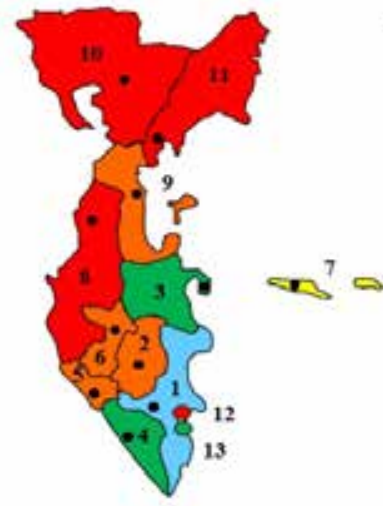

$2011 \mathrm{r}$.

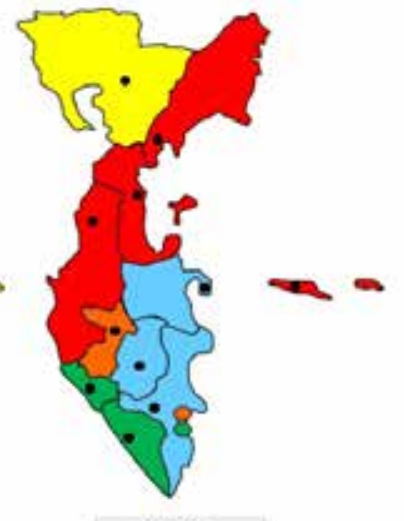

$2018 \mathrm{r}$.
Уровень заболеваммости населекия:

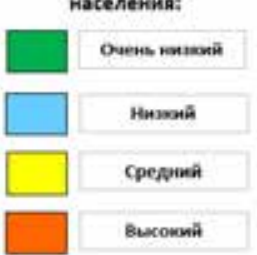

Оуень висовия

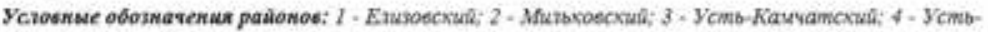

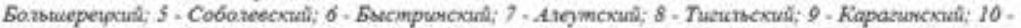

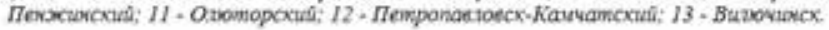

Рис. Сравнительная оценка уровня общей заболеваемости населения Камчатского края в 2011 и 2018 гг. 
гильском, Карагинском и Алеутском районах, высокий уровень в Быстринском районе и г. Петропавловске-Камчатском, средний уровень в Пенжинском районе, низкий уровень в Елизовском, Усть-Камчатском, Мильковском районах и очень низкий уровень в г. Вилючинске и Усть-Большерецком, Соболевском районах.

Сравнительный анализ полученных данных за 2011 и 2018 гг. показал, что негативные изменения по исследуемой проблеме произошли в трех районах Камчатского края. Карагинский район с высоким уровнем и Алеутский район со средним уровнем перешли в группу районов с очень высоким уровнем заболеваемости, Усть-Камчатский район с очень низким уровнем переместился в группу районов региона с низким уровнем заболеваемости.

В этот же период произошли некоторые позитивные изменения. Пенжинский район и г. Петропавловск-Камчатский с очень высоким уровнем заболеваемости перешли в группы районов со средним и высоким уровнями соответственно. Соболевский и Мильковский районы с высоким уровнем заболеваемости улучшили свои позиции, переместившись в группы районов с очень низким и низким уровнями заболеваемости соответственно. При этом существенно изменил позицию Пенжинский район, который в 2011 г. занимал лидирующую позицию в Камчатском крае по уровню заболеваемости с наибольшим количеством полученных баллов (13).

Ситуация без изменений в группах уровней заболеваемости наблюдается в шести районах Камчатского края: очень высокий уровень (Тигильский, Олюторский районы), высокий уровень (Быстринский район), низкий уровень (Елизовский), очень низкий уровень (Усть-Большерецкий район и г. Вилючинск). Наилучшее положение с 2011 г. сохранил Вилючинск, который стабильно занимает последнее место в регионе по уровню заболеваемости населения. Так же не изменил позицию Тигильский район, в котором до сих пор сохраняется напряженная ситуация по заболеваемости населения.

Позиционные и групповые изменения среди районов Камчатского края связаны с увеличением или уменьшением установленных значений по основным классам болезней. В большинстве районов Камчатского края с 2011 по 2018 гг. увеличились суммарные значения, отражающие наличие соответствующей заболеваемости (по основному классу болезней) выше среднего по региону. Например, наихудшую динамику показал Алеутский район, изменивший сумму полученных баллов с 7 в 2011 г. до 12 в 2018 г. Позитивная динамика 
произошла только в четырех районах Камчатского края (Пенжинский, Соболевский, Мильковский районы и Петропавловск-Камчатский).

Использование предложенной методики позволило дополнить вышеизложенные результаты общерегиональной информацией по заболеваемости различными классами болезней. В 2018 г. в Камчатском крае наихудшая ситуация обнаружена по классам болезней органов дыхания, пищеварения, травм и отравлений, по которым в девяти районах отмечена заболеваемость выше среднего по региону. Напряженность по данным классам болезней сохраняется с 2011 г. Наиболее благополучная региональная ситуация отмечена для классов врожденных аномалий и новообразований, по которым в 2011 и 2018 гг. наблюдалась заболеваемость населения выше среднего по региону в наименьшем количестве исследуемых районов - трех.

Таким образом, в Камчатском крае наблюдаются внутрирегиональные различия в уровне заболеваемости населения. Подтверждено, что наиболее благополучным районом по уровню заболеваемости является Вилючинск. Крайне неблагополучная ситуация сложилась в Олюторском и Тигильском районах. Представленные результаты следует учитывать с поправкой на то, что в сравнительной оценке были рассмотрены не многолетние, а однолетние значения. К тому же выделенные группы районов по уровню общей заболеваемости рассмотрены только в территориальном контексте Камчатского края. Требуются дополнительные исследования, направленные на более детальный пространственно-временной анализ заболеваемости населения Камчатского края и определение его места в российском пространстве.

Работа выполнена при поддержке гранта ДВО РАН №18-5-056 «Потенциал здоровья населения как важнейший элемент безопасности регионов Тихоокеанской России в условиях трансформаџии окружающей среды».

\section{Литература}

1. Ватлина Т.В. Влияние природных и антропогенных факторов на здоровье населения Смоленской области: дис. ... канд. геогр. наук. М., 2012. 164 с.

2. Малхазова С.М., Пестина П.В., Шартова Н.В. Здоровье населения в регионах России в начале XXI века: медико-географическая оценка // Доклады Академии наук. 2017. T. 475. №3. С. 329-332.

3. Малхазова С.М., Шартова Н.В., Тимонин С.А. Современная ситуация и тенденции изменения общественного здоровья в России // Вестник Московского университета. Серия 5: География. 2016. № 1. С. 13-20. 
4. Основные показатели здоровья населения и деятельности медицинских организаций Камчатского края за 2017-2018 годы: Стат. сборник. Вып. 18. Петропавловск-Камчатский: Камчатский краевой медицинский информационно-аналитический центр, 2019. 211 с.

5. Основные показатели здоровья населения и деятельности учреждений здравоохранения Камчатского края за 2013-2014 годы: Стат. сборник. Вып. 14. Т. 2. Петропавловск-Камчатский: Камчатский краевой медицинский информационно-аналитический центр, 2015. $210 \mathrm{c}$.

6. Основные показатели здоровья населения и деятельности учреждений здравоохранения Камчатского края за 2011-2012 годы: Стат. сборник. Вып. 12. Т. 2. Петропавловск-Камчатский: Камчатский краевой медицинский информационно-аналитический центр, 2013. 209 с.

7. Основные показатели здоровья населения и деятельности учреждений здравоохранения Камчатского края за 2015-2016 годы: Стат. сборник. Вып. 16. Т. 2. Петропавловск-Камчатский: Камчатский краевой медицинский информационно-аналитический центр, 2017. $196 \mathrm{c.}$

\section{References}

1. Vatlina T.V. Vlijanie prirodnyh $i$ antropogennyh faktorov na zdorov'e naselenija Smolenskoj oblasti. Diss. kand. geographicheskih nauk [The influence of natural and anthropogenic factors on the population health of the Smolensk Region. Doct. Diss]. Moscow, 2012. 164 p.

2. Malkhazova S.M., Pestina P.V., Shartova N.V. Public Health in the Regions of Russia at the Beginning of the Twenty-first Century: Medical-Geographical Assessment. Doklady Earth Sciences, 2017, no. 1, pp. 840-843.

3. Malkhazova S.M., Shartova N.V., Timonin S.A. Current situation and the trends of changes of the public health in Russia. Vestnik Moskovskogo Universiteta, Seriya 5: Geografiya-Moscow University Bulletin. Series 5. Geography, 2016, no. 1, pp. 13-20.

4. Osnovnye pokazateli zdorov'ya naseleniya $i$ deyatel'nosti uchrezhdenij zdravookhraneniya Kamchatskogo kraya za 2017-2018 gody: Statisticheskij sbornik. Vyp. 18. [The main indicators of public health and healthcare institutions in the Kamchatka Krai for 2017-2018: Statistical compilation. Vol. 18]. Petropavlovsk-Kamchatsky, 2019. 211 p.

5. Osnovnye pokazateli zdorov'ya naseleniya $i$ deyatel'nosti uchrezhdenij zdravookhraneniya Kamchatskogo kraya za 2011-2012 gody: Statisticheskij sbornik. Vyp. 12. T. 2. [The main indicators of public health and healthcare institutions in the Kamchatka Krai for 2011-2012: Statistical compilation. Vol. 12]. Petropavlovsk-Kamchatsky, 2013. $209 \mathrm{p}$.

6. Osnovnye pokazateli zdorov'ya naseleniya $i$ deyatel'nosti uchrezhdenij zdravookhraneniya Kamchatskogo kraya za 2013-2014 gody: Statisticheskij sbornik. Vyp. 14. T. 2. [The main indicators of public health and healthcare institutions in the Kamchatka Krai for 2013-2014: Statistical compilation. Vol. 14]. Petropavlovsk-Kamchatsky, 2015. $210 \mathrm{p}$.

7. Osnovnye pokazateli zdorov'ya naseleniya $i$ deyatel'nosti uchrezhdenij zdravookhraneniya Kamchatskogo kraya za 2015-2016 gody: Statisticheskij sbornik. Vyp. 16. T. 2. [The main indicators of public health and healthcare institutions in the Kamchatka Krai for 2015-2016: Statistical compilation. Vol. 16]. Petropavlovsk-Kamchatsky, 2017. $196 \mathrm{p}$. 